\title{
FUNDAMENTOS FILOSÓFICO-HISTÓRICOS DA PROPOSTA DOS INSTITUTOS FEDERAIS DE EDUCAÇÃO
}

\author{
V. ZATTI ${ }^{1}$, S. C. DONNER ${ }^{2}$ e E. R. JESUS ${ }^{3}$ \\ Instituto Federal do Rio Grande do Sul (IFRS) \\ vicente.zatti@canoas.ifrs.edu.br ${ }^{1}$; sandra.donner@canoas.ifrs.edu.br ${ }^{2}$, edson.jesus@canos.ifrs.edu.br ${ }^{3}$
}

Artigo submetido em fevereiro/2014 e aceito em março/2014

\section{RESUMO}

A presente pesquisa busca promover a investigação, problematização e reflexão sobre os fundamentos filosófico-históricos da proposta pedagógica dos Institutos Federais de Educação, criados pela Lei 11.892 de 2008. Buscamos através da análise dos documentos que criam, normatizam e estabelecem as diretrizes dos IFETs, de análise bibliográfica e de entrevistas, definir quais são as principais referências filosóficas e históricas que serviram de base para configuração da referida proposta pedagógica. Tais referências filosóficohistóricas serão objeto de hermenêutica crítica, a fim de que tal problematização auxilie no pensar e repensar o processo de implantação dos IFETs, que iniciou em 2008 e ainda está em andamento.

PALAVRAS-CHAVE: Educação profissional e tecnológica; filosofia da educação; história da educação profissional.

\section{PHILOSOPHICAL-HISTORICAL BACKGROUND OF THE PROPOSAL OF FEDERAL EDUCATION INSTITUTES}

\begin{abstract}
This research aims to promote research, problematizing and reflection on the philosophical and historical foundations of the pedagogical proposal of the Federal Institutes of Education created by Law 11,892 of 2008. We seek to through the analysis of documents that create, standardize and establish the guidelines of IFETs, literature review and interviews, define which major
\end{abstract}

philosophical and historical references that served as the basis for design of this pedagogic proposal. Such philosophical and historical references will be subject to critical hermeneutics to that such questioning assists in thinking and rethinking the deployment process of IFETs, which started in 2008 and still in progress.

KEYWORDS: Professional and technological education; Philosophy of education; History of vocational education. 


\section{INTRODUÇÃO}

Historicamente, até o início do século XIX, não encontramos registros de iniciativas sistemáticas quanto à educação profissional escolar no Brasil. Como nossa história é marcada pela colonização portuguesa, depois pela dependência em relação à Inglaterra, não se exigia trabalho qualificado e, por isso, não houve grande preocupação com a educação dos trabalhadores, uma vez que estávamos submetidos a uma condição de fornecedores de matéria prima. Segundo Moura (2010, p. 61), a aprendizagem dos ofícios manufatureiros era realizada pelo sistema de ajudantes/aprendizes, o que na prática significava que os menores ajudantes, enquanto auxiliavam na produção, eram aprendizes.

De acordo com o Parecer n 16/99 da Câmara de Educação Básica (CEB) e do Conselho Nacional de Educação (CNE), a origem da educação profissional escolar no Brasil remonta a 1809, quando D. João VI cria o Colégio das Fábricas. Em 1816 cria-se a Escola de Belas Artes com o objetivo de articular o ensino das ciências com o de desenho para a utilização nas oficinas mecânicas. A partir de 1840 foram construídas dez Casas de Educandos e Artífices em capitais brasileiras e em 1854 criam-se os Asilos da Infância dos Meninos Desvalidos que ensinavam as primeiras letras e encaminhavam os egressos para as oficinas. Em 1861 cria-se o Instituto Comercial no Rio de Janeiro, para a capacitação de pessoas para o preenchimento dos cargos públicos. Ao longo do século XIX foram criadas entidades destinadas a dar amparo a crianças órfãs e abandonadas, o que marca o caráter assistencialista da origem da educação profissional no Brasil.

No início do século $X X$, o nascente processo de industrialização passa a exigir operários minimamente qualificados, então a preocupação principal deixa de ser o atendimento de menores e órfãos e passa ser a preparação de operários para o exercício profissional. Em 1906 o ensino profissional passou a ser atribuição do Ministério da Agricultura, Indústria e Comércio. Em 1909, Nilo Peçanha criou as Escolas de Aprendizes Artífices, e em 1910 instalou-as em 19 unidades da Federação. Até a década de 30 foram instaladas escolas para atender a necessidade de trabalhadores no campo e na indústria, mas de uma forma dual, com percurso educativo claramente definido e diferenciado para a elite e para os filhos da classe trabalhadora. Quem continuaria no ensino superior faria os cursos primário e ginasial. Os cursos básico agrícola, técnico comercial e normal, tinham caráter terminal, pois eram voltados para necessidades imediatas do setor produtivo. Em 1937 as Escolas de Aprendizes Artífices foram transformadas nos liceus industriais.

Na década de 40 é realizada a Reforma Capanema (nome dado em função do então Ministro da Educação Gustavo Capanema), que estabeleceu leis específicas para a formação profissional em cada ramo da economia e para a formação de professores de ensino médio. Nesse contexto são criados os exames de adaptação que permitiam aos concluintes dos cursos técnicos profissionalizantes a possibilidade de retomar uma trajetória acadêmica e continuar os estudos de nível superior, o que foi uma primeira tentativa e aproximação entre o ramo secundário propedêutico e os cursos profissionalizantes de nível médio. Em 1942 os liceus passam a se chamar Escolas Industriais e Técnicas, e em 1959 são chamadas Escolas Técnicas Federais, configuradas como autarquias. Também ocorre a criação do SENAI em 1942, seguido do SENAC em 1946, e dos demais " $\mathrm{S}$ " ao longo das décadas seguintes, o que demonstra a opção governamental de repassar à iniciativa privada a tarefa da preparação do trabalhador. (cf. MOURA, 2010, p. 65). 
Segundo o Parecer CNE/CEB no 16/99, apenas na década de 50 é que se passou a permitir a equivalência entre os estudos acadêmicos e profissionalizantes, quebrando, em parte, a rigidez entre os dois ramos de ensino e entre os vários campos do próprio ensino profissional. A Lei Federal n. $-1.076 / 50$ permitia que concluintes de cursos profissionais pudessem continuar estudos acadêmicos nos níveis superiores, desde que prestassem exames das disciplinas não estudadas naqueles cursos e provassem possuir o nível de conhecimento indispensável à realização dos aludidos estudos. Entretanto, a plena equivalência entre todos os cursos do mesmo nível, sem necessidade de exames e prova de conhecimentos, só veio a ocorrer a partir de 1961, com a promulgação da Lei Federal n.․ 4.024/61, a primeira Lei de Diretrizes e Bases da Educação Nacional.

Em 1971, sob as asas dos militares, é promovida uma profunda reforma na educação básica com a Lei 5.692/71, que tentou estruturar o nível médio brasileiro como sendo profissionalizante para todos. Com essa reforma a escolarização dos 11 aos 14 anos (5a a 8a séries do então 1o grau) passou a integrar a fase inicial dos estudos. O então 2ㅇ grau adquiriu um caráter de profissionalização obrigatória. Segundo Moura (2010, p. 68), em vez de ampliar a duração do 20 grau para incluir os conteúdos de forma integrada aos conhecimentos das ciências, das letras e das artes, o que houve foi a redução dos últimos em favor dos primeiros e, consequentemente, direcionando a educação do período para um caráter instrumental e de baixa complexidade. Como tal reforma foi feita sem um suporte financeiro para construção de, por exemplo, laboratórios, proliferaram-se cursos como Técnico em Administração, Técnico em Contabilidade, Técnico em Secretariado, etc, ocorrendo a saturação de profissionais dessas áreas. Nesse período, nas Escolas Técnicas Federais (EFETs) e Escolas Agrotécnicas Federais (EAFs), a realidade foi distinta, pois tais escolas, segundo Moura (2010, p. 69) em função das condições diferenciadas que tiveram, não mantiveram seus currículos nos limites restritos da instrumentalidade para o mundo do trabalho e, mesmo com sua atuação principalmente na vertente industrial, firmaram-se como referência de qualidade na formação de técnicos de nível médio.

Segundo o Parecer CNE/CEB no 16/99, a criação da atual LDB (Lei de Diretrizes e Bases da Educação Nacional - Lei Federal n. 9.394/96) configura a identidade do ensino médio como uma etapa de consolidação da educação básica, de aprimoramento do educando como pessoa humana, de aprofundamento dos conhecimentos adquiridos no ensino fundamental para continuar aprendendo e de preparação básica para o trabalho e a cidadania. A LDB traz uma concepção de educação profissional que representa a superação dos enfoques assistencialista e economicista.

Após a promulgação da LDB de 1996, o Decreto no 2.208/1997 estabeleceu a separação entre o ensino médio e educação profissional. $O$ ensino médio retoma seu sentido puramente propedêutico, enquanto os cursos técnicos, obrigatoriamente separados do ensino médio, se restringem à formação técnica. Foi estabelecido duas formas de oferecimento do ensino técnico: subsequente para quem já concluiu o ensino médio e concomitante ao ensino médio, modalidade em que o estudante pode fazer ao mesmo tempo o ensino médio e o ensino técnico, mas com matrículas e currículos diferentes, na mesma ou em instituições diferentes. De acordo com Ramos (2010, p.42), a lei de Diretrizes e Bases da Educação Nacional (LDB) apresenta a educação profissional como um direito, mas o Decreto no 2.208/97 promoveu a desvinculação do ensino médio e técnico, o que acabou eximindo o sistema de ensino público da responsabilidade de ofertá-lo e financiá-lo.

Na década de 90 com a inserção do Brasil no projeto neoliberal, há um avanço quantitativo no ensino fundamental, que é acompanhado por um dualismo e diferenciação, mais crianças têm 
acesso à escola, mas a uma escola pública para pobres e/ou filhos de trabalhadores, que não promove o acesso efetivo e democrático ao conhecimento. Essa opção neoliberal estabeleceu a reiteração do dualismo entre educação geral e específica, humanística e técnica, o que resulta na fraca relação entre educação básica e formação técnico-profissional. Para Frigotto $(2010$, p. 33) no âmbito da Educação Profissional e Tecnológica, o governo da década de 90 valeu-se do discurso da tecnologia e da tecnologia dos discursos, para dissimular o tecnicismo. O decreto no 2.208/97 induziu a maioria dos Centros Federais de Educação Tecnológica (CEFETs) a uma formação profissional estreita e desvinculada de uma formação mais ampla do ser humano historicamente situado $^{1}$. Nesse contexto o Sistema S, especialmente o SENAI, passa a denominar vários de seus departamentos regionais de unidades de negócio, o que mostra a condução do interesse privado em uma instituição que é mantida com fundo público.

O Decreto no 5.154/04 busca resgatar a perspectiva do ensino médio como educação politécnica ou tecnológica, contrariando a perspectiva de aligeiramento e profissionalização compulsória da Lei $\mathrm{n}^{\circ}$ 5.692/71 e o dualismo imposto pelo Decreto no 2.208/97. Segundo Ramos (2010, p. 44), o ideário da politécnica diz respeito ao domínio dos fundamentos científicos da técnica, buscando romper a dicotomia entre educação básica e técnica, resgatando o princípio da formação humana em sua totalidade e o desenvolvimento de todas as potencialidades humanas (ciência, cultura, humanismo, tecnologia). O tempo de realização do ensino médio integrado amplia-se de três para quatro anos para permitir uma formação que articule ciência, cultura e trabalho, estabelecendo condições para a superação tanto do academicismo quanto da visão profissionalizante adestradora (cf. Frigotto, 2010, p. 34). Esse decreto, além da educação profissional técnica de nível médio nas formas concomitante e subsequente, retoma a possibilidade da forma integrada de ensino.

Em 2008 o Ministério da Educação focou a política de educação profissional em três grandes objetivos: expansão da rede federal, criação dos Institutos Federais de Educação, Ciência e Tecnologia (IFETs) e tentativas de mudança no Sistema S. A Lei 11.892/08 criou o novo modelo de instituição de educação profissional e tecnológica, os IFETs, que foram criados a partir do potencial instalado dos CEFETs, escolas técnicas e agrotécnicas federais e escolas vinculadas às universidades federais. O Artigo 20 da Lei 11.892/08 define os Institutos Federais da seguinte forma: "Os Institutos Federais são instituições de educação superior, básica e profissional, pluricurriculares e multicampi, especializados na oferta de educação profissional e tecnológica nas diferentes modalidades de ensino, com base na conjugação de conhecimentos tecnológicos com as suas práticas pedagógicas" Essas instituições surgem com o propósito de superar o dualismo, contido na educação brasileira, e não formar apenas mão de obra para atender a necessidade de crescimento econômico do capitalismo. Seu foco é mais ampliado, buscando o diálogo com a sociedade como um todo: "O foco dos institutos federais é a promoção da justiça social, da equidade, do desenvolvimento sustentável com vistas à inclusão social, bem como a busca de soluções técnicas e geração de novas tecnologias". (JURACY, 2009, p. 8).

A partir deste breve histórico, situando a criação dos Institutos Federais dentro da sociedade brasileira, fica clara a importância do mapeamento das ideias que fundamentaram a escolha deste modelo de educação, já que, como ocorre em outros países, foi realizada uma opção

\footnotetext{
${ }^{1}$ Frigotto (2010) cita a criação do Plano Nacional de Qualificação do Trabalhador (PLANFOR), que instituiu cursos profissionalizantes em sua grande maioria desprovidos de uma base científica, técnica e de cultura mais geral.
} 
governamental pelo formato de Institutos com base na verticalização do ensino e da vinculação entre ensino médio, cursos tecnológicos e licenciaturas, com vistas à implantação de pósgraduação.

\section{REFERENCIAL TEÓRICO}

É necessário analisarmos os fundamentos filosófico-históricos do projeto dos IFETs para estabelecermos se realmente há essa relação de ruptura com um histórico dual e tecnicista da educação profissional e tecnológica no Brasil. Tal análise também poderá revelar bases que eventualmente ficam ocultas sob o discurso oficial, que é um discurso otimista e de autoafirmação do projeto. Reforçamos que educação profissional e tecnológica, quando restrita aos seus aspectos técnicos, está incorrendo nos mesmos erros do positivismo ao desconsiderar que ciência e a técnica mantém uma inevitável referência ao mundo da vida. São sobre as experiências précientíficas do mundo da vida que originariamente constituem-se as próprias ciências. Por maior objetividade que apresentem e por mais autônomas que sejam, é no mundo da vida que ciência e técnica encontram seu fórum de validade. Porque nosso contato com o mundo é mediado linguisticamente, o mundo se exime igualmente tanto do acesso direto do sentido como de uma constituição direta, através das formas de entendimento. A objetividade do mundo, que supomos ao falar e agir, está de tal modo entrelaçada com a intersubjetividade do entendimento sobre algo no mundo, que não damos um passo atrás desta correlação, da qual não nos podemos desviar do horizonte revelado e linguisticamente partilhado. (HABERMAS, 2002b, p. 56).

Por isso, segundo Habermas (1989, p. 75-76), o uso comunicativo da linguagem pressupõe o uso cognitivo mediante o qual dispomos de conteúdos proposicionais: e, o inverso, o uso cognitivo da linguagem, pressupõe o comunicativo porque as orações assertórias só podem empregar-se em atos de fala constatativos. "Uma situação de entendimento possível exige que ao menos os falantes/ouvintes estabeleçam uma comunicação simultaneamente em ambos planos: no plano da intersubjetividade, em que os sujeitos falam entre si, e no plano dos objetos (ou estados de coisas) sobre o que se entendem." (HABERMAS, 1989, p. 83, tradução nossa).

O mundo da vida, como já vimos, é o "pano de fundo" apenas intuitivamente presente e absolutamente certo, do qual se desprendem as esferas daquilo sobre o qual se pode alcançar em cada caso um acordo falível. (cf. HABERMAS, 2002a, p.169). É algo que todos nós temos sempre presente, de modo intuitivo e não-problemático, como sendo uma totalidade pré-teórica. (cf. HABERMAS, 2002c, p. 48). "O mundo da vida constitui, pois, o contexto da situação de ação, ao mesmo tempo, ele fornece os recursos para os processos de interpretação com os quais os participantes da comunicação procuram suprir a carência de entendimento mútuo que surgiu em cada situação de ação." (HABERMAS, 2003, p. 167). Segundo Stein (2004, p. 46), o conceito de mundo da vida se liga à uma racionalidade que é a priori, enquanto ele é o limite para trás do qual não se pode recuar, é o já sempre dado. É esse pano de fundo intersubjetivamente partilhado que possibilita o entendimento entre os sujeitos. "Os processos de entendimento mútuo do mundo da vida carecem por isso de uma tradição cultural em toda sua latitude e não apenas das bênçãos da ciência e da técnica." (HABERMAS, 2003, p. 33). Ou seja, o progresso técnico e científico não tem uma legitimidade própria, eles estão interligados e interdependentes com esferas como ética, estética, política. Segundo Freire $(1982$, p.97) o conhecimento é o processo que implica ação e reflexão do homem sobre o mundo, de modo que a ciência está sempre relacionada com outras 
esferas da vida. A preocupação com a verdade e com a rigorosidade científica, não dá à ciência neutralidade. Por isso a educação profissional e tecnológica precisa manter seu horizonte formativo amplo, abordando a vida humana em sua amplitude. Tal abertura ao mundo da vida, para que se evitem distorções positivistas, deve ocorrer não apenas nos cursos de ensino médio integrado, mas em todos os níveis de educação profissional e tecnológica.

Como a técnica e a ciência mantém ligação com outras esferas do mundo da vida, e, encontram seu fórum de validade no mundo da vida, a alegação de neutralidade e objetividade da ciência só pode ser pensada de forma distorcida, através da redução da técnica e da ciência aos seus aspectos instrumentais. A autocompreensão cientificista das ciências, que chega à supremacia como teoria da ciência, tende a substitui o conceito filosófico de conhecimento. Conhecimento torna-se, enquanto tal, reconhecido e aceito quando apenas idêntico a conhecimento científico. A ciência fica, antes de mais nada, delimitada à esfera de seus objetos e está, assim, separada de outras realizações cognitivas (HABERMAS, 1982, p. 100). Ou seja, tal redução do conhecimento ao conhecimento científico ocorre quando a racionalidade é reduzida à racionalidade instrumental, em nível social isso se manifesta através da colonização do mundo da vida pelo sistema. Aí mais uma vez a educação integrada, que educa para o pensar crítico, faz-se necessária para formar um homem capaz de tematizar discursivamente essas distorções. A questão que se coloca aqui é esta: evitar as distorções ideológicas geradas pelo positivismo, cientificismo e tecnicismo. "Se se considera que a tecnologia não é somente necessária, mas que representa uma parte do desenvolvimento natural do homem, a questão que se apresenta aos revolucionários é saber como evitar os desvios míticos da tecnologia" (FREIRE, 1980, p. 93).

Autores como o filósofo Jurgen Habermas afirmam que: como a ciência não é neutra, não possui um status auto-legitimador, ela depende de um contexto de sentidos e fundamentos que a validam. Portanto, ao tratar dos fundamentos da ciência, somos remetidos para além da ciência. Desse modo, a análise dos fundamentos da proposta de educação profissional e tecnológica dos IFETs, também buscará o que está além do discurso oficial.

\section{METODOLOGIA}

A presente pesquisa é desenvolvida a partir de análise bibliográfica, da literatura filosófica e educacional pertinente, análise documental relacionada à educação profissional e tecnológica e entrevistas (presencial e/ou por e-mail) com pessoas que participaram da concepção da proposta dos IFETs. Quanto aos documentos, são analisados principalmente aqueles relacionados à criação e normatização dos Institutos Federais de Educação. Refere-se a uma pesquisa qualitativa, que utiliza procedimentos metodológicos da fenomenologia para desenvolver uma hermenêutica crítica, capaz de desvelar as intencionalidades que compõe os discursos e elaborar conceitos significativos para a compreensão do problema em questão: qual seja, a compreensão da novidade no campo do ensino que representou a criação dos Institutos Federais de Educação no contexto da educação profissional brasileira.

Nos primeiros dois meses estivemos concentrados na leitura da bibliografia e na análise da legislação. Tais leituras foram debatidas entre o coordenador do projeto, os colaboradores e o bolsista em reuniões quinzenais. Os textos, além de focarem o desenvolvimento dos Institutos Federais no Brasil, também trazem exemplos sobre como a educação profissional é tratada nos demais países da América Latina, Estados Unidos e Europa. 
No terceiro mês tratamos da elaboração do roteiro das entrevistas. No quarto e quinto mês, realização das entrevistas. Como suporte para as entrevistas, utilizamos as técnicas desenvolvidas na História Oral e na organização e preparo das entrevistas na área de sociologia e antropologia. As entrevistas são realizadas com políticos e intelectuais que foram protagonistas na criação dos Institutos Federais. Com isso, buscou-se uma rede de contatos e, porque não, de versões. Essas informações trarão uma riqueza à pesquisa, pois, além da "versão oficial" será possível o contato com outras falas que eventualmente, irão corroborar ou contradizer o primeiro entrevistado.

Do sexto até o décimo primeiro mês, focamos na transcrição das entrevistas, feita de acordo com as regras propostas pela Fundação Getúlio Vargas para elaboração de fontes de História Oral. A partir do material escrito fizemos uma problematização teórico-prática do material investigado.

\section{RESULTADOS PARCIAIS}

Este projeto está ligado a uma discussão que tem ocorrido de forma silenciosa, dentro dos Institutos Federais, onde, se busca, através de uma retomada da história dos institutos, uma identidade. Afirmar-se como uma instituição autônoma é um desafio para os diversos Câmpus que surgiram nos últimos anos. Neste sentido, este trabalho pretende contribuir para o debate.

Nossas discussões sobre os fundamentos da educação profissional, indicam que, quando restrita aos seus aspectos de formação técnica, está incorrendo nos mesmos erros do positivismo ao desconsiderar que ciência e a técnica mantém uma inevitável referência ao mundo da vida. São sobre as experiências pré-científicas do mundo da vida que originariamente constituem-se as próprias ciências. Por maior objetividade que apresentem e por mais autônomas que sejam, é no mundo da vida que ciência e técnica encontram seu fórum de validade.

Desse modo, a educação profissional que se pretende emancipatória não pode estar restrita à transmissão estática de conhecimentos. Primeiro, não se refere apenas ao ensino de conhecimentos. Como o pano de fundo da racionalidade é o mundo da vida, a educação profissional emancipatória se volta à formação do homem de forma integral, ou seja, educação emancipatória envolve política, ética, estética, etc, a vida humana como um todo. Segundo, ao se referir aos conhecimentos, volta-se à apreensão dos fundamentos científicos e não ao treinamento, isso porque, o conhecimento não é estático, não está amparado pela objetividade pretendida pelo positivismo. Integrar os conhecimentos técnico-científicos com a totalidade do humano, envolve o reacoplamento da técnica e da ciência ao mundo da vida, instância do agir comunicativo. Para isso o modelo de racionalidade que guia o processo educativo não deve estar restrito ao aspecto instrumental, e sim, ser uma racionalidade ampla que definimos em nossa pesquisa através do conceito de razão comunicativa de Habermas. Uma formação pautada por tal concepção de racionalidade se desdobra em educação que não se aparta do mundo da vida e supera a ideologia tecnocrática de neutralidade e autossuficiência dos saberes técnico-científicos.

Uma abordagem tecnicista, restrita aos aspectos instrumentais, assume um caráter ideológico de manutenção e reprodução de uma estrutura social opressora. Nesse sentido, a proposta dos Institutos Federais de Educação representa um avanço em educação profissional na medida em que seus princípios pedagógicos buscam a produção de tecnologias sociais e, não apenas tecnologias úteis ao capital. Tal proposta, engajada com a transformação social, possui 
como pano de fundo teórico concepções vinculadas ao materialismo histórico. Tal concepção teórica, encaminha uma proposta de educação profissional voltada para a integralidade da formação do ser humano.

\section{REFERÊNCIAS}

1. AMADO, Janaína e FERREIRA, Marieta de Moraes. Usos \& abusos da história oral. Rio de Janeiro: Editora da Fundação Getúlio Vargas, 1998.

2. BRASIL. Decreto $\mathbf{n}^{\circ} \mathbf{5 . 1 5 4}$ de 23 de julho de 2004.

3. BRASIL. Decreto no $\mathbf{2 . 2 0 8}$ de 17 de abril de 1997.

4. BRASIL. Parecer CNE/CEB no 16 de 05 de outubro de 1999. Trata das Diretrizes Curriculares Nacionais para a Educação Profissional de Nível Técnico.

5. BRASIL. Lei no $\mathbf{1 1 . 8 9 2}$ de 29 de dezembro de 2008.

6. FREIRE, Paulo. Ação cultural para a liberdade. 6a ed. Rio de Janeiro: Paz e Terra, 1982.

7. Conscientização: teoria e prática da libertação: uma introdução ao pensamento de Paulo Freire. Trad. Kátia de Mello e Silva. 3a ed. São Paulo: Editora Moraes, 1980.

8. FRIGOTTO, Gaudêncio. A relação da educação profissional e tecnológica com a universalização da educação básica. In: MOLL, Jaqueline (Org.). Educação Profissional e Tecnológica no Brasil contemporâneo. Porto Alegre: Artmed, 2010, p. 25-41.

9. HABERMAS, Jürgen. A crise de legitimação no capitalismo tardio. Rio de Janeiro: Tempo Brasileiro, 2002a.

10. Agir comunicativo e razão destrancendentalizada. Trad. Lucia Aragão. Rio de Janeiro: Tempo Brasileiro, 2002b.

11. Consciência moral e agir comunicativo. Trad. Guido A. de Almeida. $2 \underline{a}$ ed. Rio de Janeiro, 2003.

12. C__ Conhecimento e interesse. Rio de Janeiro: Zahar Editores, 1982.

13. _. Pensamento pós-metafísico: estudos filosóficos. Trad. Flávio Beno Siebeneichler. 2aㅡ ed. Rio de Janeiro: Tempo Brasileiro, 2002c.

14. Teoria de la acción comunicativa: complementos y estúdios prévios. Madrid: Cátedra, 1989.

15. JURACY, Caetana. (org.). Institutos Federais Lei 11.892, de 29/12/2008. Comentários e Reflexões. Natal: IFRN, 2009.

16. MOURA, Dante Henrique. Ensino médio e educação profissional. In: MOLL, Jaqueline (Org.). Educação Profissional e Tecnológica no Brasil contemporâneo. Porto Alegre: Artmed, 2010, p. 58-79.

17. RAMOS, Marise. O Ensino Médio integrado. In: MOLL, Jaqueline (Org.). Educação Profissional e Tecnológica no Brasil contemporâneo. Porto Alegre: Artmed, 2010, p. 42-57.

18. STEIN, Ernildo. Mundo vivido: das vicissitudes e dos usos de um conceito da fenomenologia. Porto Alegre: EDIPUCRS, 2004. 